\title{
Assessing the efficiency of protected areas to represent biodiversity: a small island case study
}

\author{
MARTA VERGÍliO ${ }^{1 *}$, CATARINA FONSECA ${ }^{1}$, HELENA CALADO ${ }^{1}$, PAULO A.V. BORGES ${ }^{2}$, \\ RUI BENTO ELIAS ${ }^{3}$, ROSALINA GABRIEL ${ }^{2}$, ANTÓNIO MARTINS ${ }^{1}$, EDUARDO AZEVEDO ${ }^{4}$ \\ AND PEDRO CARDOSO 2,5 \\ ${ }^{I}$ CIBIO - Research Center in Biodiversity and Genetic Resources/InBIO - Associate Laboratory, University of the Azores, Rua da Mãe de Deus, \\ 13-A, Ponta Delgada 9501-801, Portugal, ${ }^{2}$ cE3c-Centre for Ecology, Evolution and Environmental Changes/Azorean Biodiversity Group and \\ Universidade dos Açores - Departamento de Ciências e Engenharia do Ambiente, Rua Capitão João d'Ávila, São Pedro, $9700-042$ Angra do \\ Heroismo, Terceira, Azores, Portugal, ${ }^{3}$ cE3c - Centre for Ecology, Evolution and Environmental Changes/Azorean Biodiversity Group and \\ Universidade dos Açores - Departamento de Ciências Agrárias, Rua Capitão João d'Á́vila, São Pedro, 9700-042 Angra do Heroismo, Terceira, \\ Azores, Portugal, ${ }^{4}$ Center of Climate, Meteorology and Global Change of the University of the Azores (CCMMG-CITA-A) - Departamento de \\ Ciências Agrárias, Universidade dos Açores, Angra do Heroísmo, Portugal and ${ }^{5}$ Finnish Museum of Natural History, University of Helsinki, \\ P.O. Box 17, 00014 Helsinki, Finland
}

Date submitted: 30 July 2015; Date accepted: 23 April 2016; First published online 6 June 2016

\section{SUMMARY}

Protected areas (PAs) have been selected using either subjective or objective criteria applied to an extremely limited subset of biodiversity. Improved availability of species distribution data, better statistical tools to predict species distributions and algorithms to optimize spatial conservation planning allow many impediments to be overcome, particularly on small islands. This study analyses whether 219 species are adequately protected by PAs on Pico Island (the Azores, Portugal), and if they are as efficient as possible, maximizing species protection while minimizing costs. We performed distribution modelling of species' potential distributions, proposed individual conservation targets (considering the context of each species in the archipelago and their current conservation status) to determine the efficiency of current PAs in meeting such targets and identify alternative or complementary areas relevant for conservation. Results showed that current PAs do not cover all taxa, leaving out important areas for conservation. We demonstrate that by using optimization algorithms it is possible to include most species groups in spatial conservation planning in the Azores with the current resources. With increasing availability of data and methods, this approach could be readily extended to other islands and regions with high endemism levels.

\footnotetext{
*Correspondence: Marta Vergílio e-mail: marta.hs.vergilio@uac.pt *Supplementary material can be found online at http:// dx.doi.org/10.1017/S037689291600014X
}

Keymords: conservation targets, genetic algorithms, protected areas, small islands, spatial conservation planning, species distribution modelling

\section{INTRODUCTION}

Protected areas (PAs) are essential tools for slowing the loss of biological diversity (Dudley et al. 2006). Historically, the location of PAs was based on conservation goals applied to an extremely limited subset of data, usually using vertebrates, or was predominantly based on opportunities, aesthetics or policy strategies (Margules et al. 2000; Pressey 1994). This led to the protection of areas with lack of value for commercial land uses or human settlements, but which were not necessarily ecologically relevant (Pressey 1994).

The equilibrium between biodiversity conservation goals and anthropogenic constraints is particularly challenging on small islands, where space is extremely limited and natural resources and human activities can scarcely be separated (Calado et al. 2014 a). Island ecosystems have a high level of uniqueness, mostly resulting from their geographical isolation, and contribute to global biodiversity disproportionately to their land area (Whittaker \& Fernández-Palacios 2007). Many island species are extremely restricted in space and highly threatened by land use conversion, invasive species and climate change, more so than continental species (Kueffer et al. 2010), and thus require urgent protection (Calado et al. 2014 a). In territories with limited space, such as small islands, natural resources and economic opportunities, the classification of PAs and resulting restrictions often collide with the human use of resources and economic expectations (Margules et al. 2000), even if PAs also create extremely relevant economic opportunities such as nature tourism.

Multiple objectives, such as simultaneously developing coastal recreational activities and preserving coastal 
ecosystems, are the basis for all regional development policies and small islands have particularly limited options for achieving these. Therefore, the selection of PAs must be carefully considered in order to guarantee the achievement of conservation goals and surpass the limitations imposed by islands. The big question is whether correct allocation of land uses and resources and appropriate $\mathrm{PA}$ classifications are being made.

Small islands present rare opportunities to include a major proportion of species in conservation planning. The reduced number of species compared with similar areas on the mainland means that it is possible to gather reliable information on many taxa, including less considered and taxonomically difficult taxa such as arthropods, snails and bryophytes. Species distribution models should include all available data at a global level for each species, as data encompassing only a fraction of the environmental envelope occupied by the species will cause bias in the models. As many oceanic island species are strict endemics, either of particular islands or of a given archipelago, it is relatively easy to compile all available data at a global scale for most. Increasing availability of extensive distribution data for most species in selected regions, statistical tools to more accurately predict species distributions, and algorithms to optimize spatial conservation planning (e.g., Marxan, Zonation and Prion software) allow for the compilation and analysis of data to help solve conservation problems (Margules et al. 2000). Algorithms developed to support area selection are also useful to assess the adequacy of existing PAs through gap analysis (Margules et al. 2000; Moilanen et al. 2009; Vasconcelos et al. 2012; Fajardo et al. 2014). Combining species distribution models (SDMs) and site selection methods may contribute to an optimal island PA design.

The Azores archipelago, a Portuguese autonomous region, consists of a group of nine small islands located in the North Atlantic. It is the northernmost archipelago of the Macaronesian Biogeographic Region and presents distinctive characteristics in terms of climate and species composition, with hundreds of endemic species (Borges et al. 2005; 2010; Cardoso et al. 2008). A network of PAs encompassing all islands and marine areas has been shaped over the years to protect such unique taxa. The network, resulting from the most recent reclassification process (Calado et al. 2009), is composed of one Island Natural Park (INP) on each of the nine islands, and a single Marine Park. Each INP comprises several management units assigned to an International Union for Conservation of Nature (IUCN) category, attempting to highlight the link between its statutory level, natural and cultural values and required management actions. Yet, the problem of where to locate the areas and their borders still remains. No new objective area prioritization studies were performed during the last $\mathrm{PA}$ reclassification process due to a lack of time and resources (Calado et al. 2009). Therefore, there is no scientific evidence that the current delimitation of the INPs is the best to protect native habitats and conserve species.
In this study, we analyse whether 219 Azorean indigenous species covering major taxonomic groups (bryophytes, vascular plants, molluscs, arthropods and vertebrates) are adequately safeguarded by PAs on Pico Island. The efficiency of these PAs was also analysed, that is, do PAs maximize species protection while minimizing costs? Our study follows four steps: (i) use of SDMs to estimate the potential distribution of species; (ii) proposal of individual conservation targets based on the context of each species in the archipelago and their current conservation status, here understood as the minimum percentage of the total occurrence area (number of occurrences or territory area) that allows species to persist over time and should be included inside PAs; (iii) determination of the efficiency of current PAs; and (iv) identification of areas of high priority for conservation.

\section{METHODS}

\section{Study area}

This study is focused on Pico Island (Fig. 1), the second largest and most recent Azorean island, covering an area of $447 \mathrm{~km}^{2}$, with $152 \mathrm{~km}$ of coastline, and reaching $2351 \mathrm{~m}$ altitude at the top of its volcano, Mount Pico, located in the western part of the island.

On Pico, as on the other Azorean Islands, the landscape has prominent streams in eroded volcanic rocks, as well as vast lava flows and active volcanoes (Condé et al. 2002). The territory mainly includes agriculture and pasture fields, forest stands and diverse natural communities, namely coastal and inland wetlands, peat bogs and several types of native forest and shrubland (Costa et al. 2013). The development of monocultural landscapes for pastures and forests increased the fragmentation of natural ecosystems and changed the biodiversity in many areas of the archipelago, giving rise to the expansion of non-indigenous and invasive species (Silva et al. 2006) and greater homogenization of communities (Florencio et al. 2013).

Pico's INP is composed of 22 areas (Fig. 2) including four nature reserves, one natural monument, eight $P A s$ for habitat/species management, six protected landscapes and three PAs for resource management (Fig. S1.1 in Appendix S1).

\section{Species occurrence data}

Presence data for bryophytes, vascular plants, molluscs, arthropods and vertebrates were obtained from the Azorean Biodiversity Portal (www.atlantis.angra.uac.pt/ atlantis/common/index.jsf), based on a regional species database, ATLANTIS, which draws on literature dating back to the 19th century, for approximately 5000 species. Each record includes information on location precision, classified in four levels: (1) very precise location, usually UTM point (Universal Transverse Mercator coordinate system) data; (2) location not exceeding $\left.25 \mathrm{~km}^{2} ; 3\right)$ imprecise location $\left(>25 \mathrm{~km}^{2}\right)$ on a given island; and (4) only island data (Borges et al. 2010). 


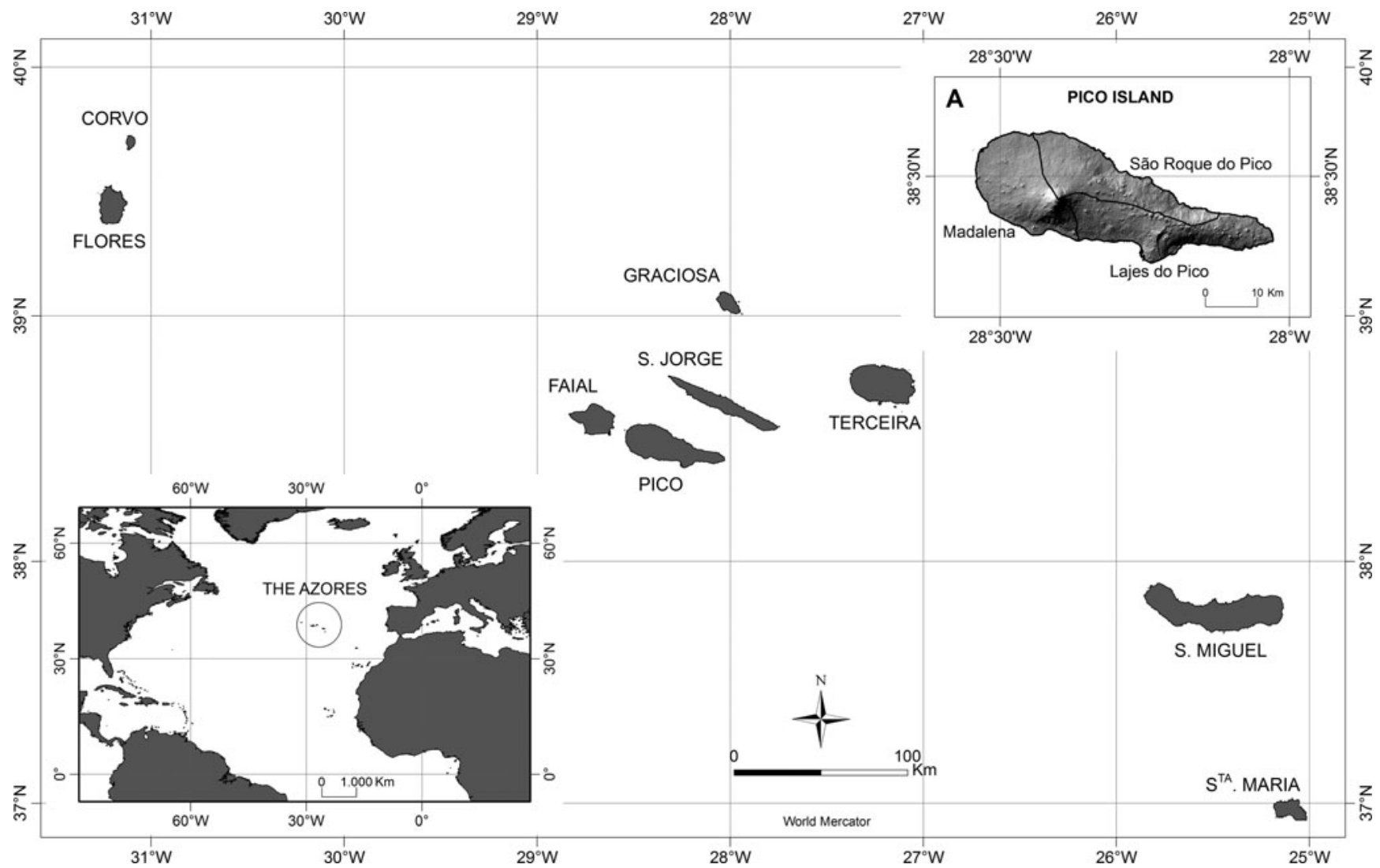

Figure 1 Location of the Azores archipelago (Portugal). (a) Pico Island.

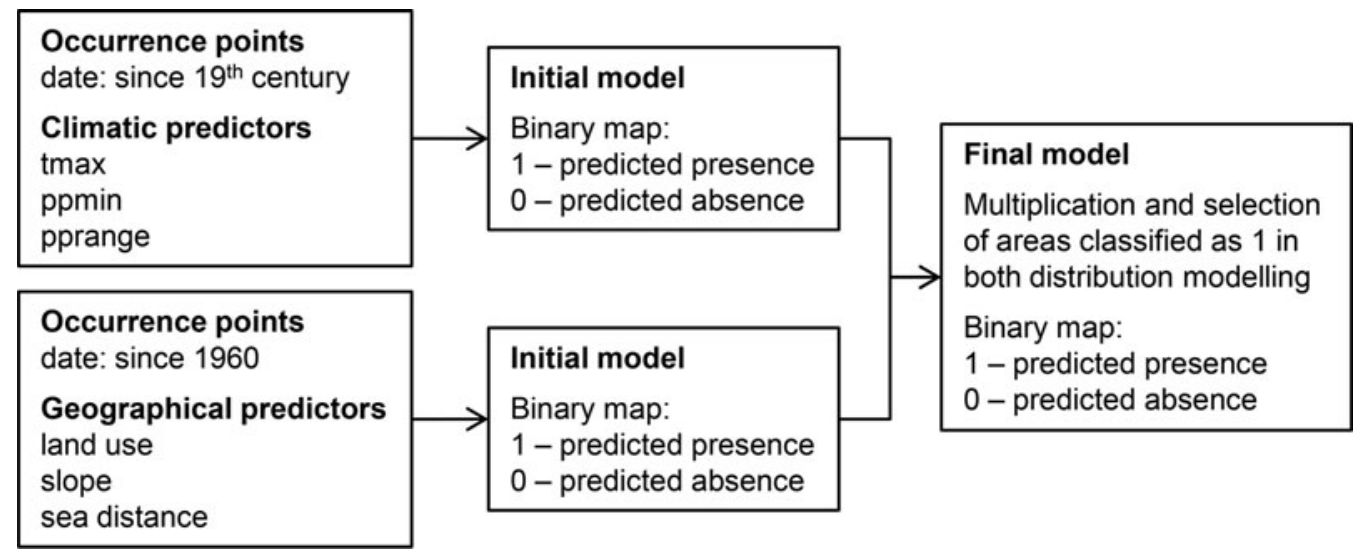

Figure 2 Representation of the scheme combining predictors. The initial model combines climatic predictors (ppmin = Minimum annual precipitation; pprange $=$ Annual range precipitation; $\operatorname{tmax}=$ Maximum annual temperature), and the final model combines geographical predictors.

In this study, we selected only data with a precision of 1 or 2 , totalling around 76000 records from 219 species.

The 219 selected species include: (1) Azorean endemics occurring on Pico Island, due to species uniqueness and importance (169 species); (2) native but non-endemic bryophytes (45 species); and (3) other legally protected species (one vascular plant and four vertebrates). Native nonendemic bryophytes were included considering the reduced number of endemics and the importance of non-endemic species to the structure of the Azorean forests (Gabriel et al. 2011). We included bryophytes with conservation concern identified on the Azorean Biodiversity Portal as rare (R), endangered $(\mathrm{E})$, threatened $(\mathrm{T})$, regionally threatened (RT) or vulnerable $(\mathrm{V})$, as long as expert opinion clearly suggested that the species' global climatic range was covered in the Azores (due to limitations of SDMs). Legally protected species included those listed as endangered in any official document (Cardoso et al. 2008), the 'Habitats' Directive 
(Council Directive 92/43/EEC), the 'Birds' Directive (Council Directive 2009/147/EC) and the Azorean Regional Legislative Decree of Nature Conservation and Biodiversity Protection (Regional Legislative Decree No. 15/2012/A). The latter also comprises the Bern Convention (Convention on the conservation of European wildlife and natural habitats), the OSPAR List of Threatened and/or Declining Species and Habitats and the Agreement on the Conservation of AfricanEurasian Migratory Waterbirds. The 219 species included 51 bryophytes, 57 vascular plants, 13 molluscs, 82 arthropods and 16 vertebrates.

\section{Species distribution modelling}

Even taking into account all previously published records for each species, most distributions were still considered incomplete. To overcome this limitation, we modelled the distribution of all species except vertebrates (16 species) and troglobionts (seven species). Vertebrates were not modelled as their distribution data were considered complete. Troglobionts, that is, exclusive cave species (Cixius azopicavus, Lithobius obscurus azoreae, Pseudoblothrus vulcanus, Rugathodes pico, Trechus montanheirorum, T. pereirai and T. picoensis) were not modelled as the climatic conditions they live in are considerably different from those at the surface, for which we had data. Moreover, the scattered distribution of caves precludes them from easily expanding their distribution beyond that already known, so we considered point data to be a sufficient proxy for the real distribution.

Presence-only SDMs, as used here, are the best available option when absence data is not available. Presence-only SDMs use presence data of species and relate them to the environmental and/or spatial characteristics of the study area through background sampling, allowing the creation of maps with the relative climate/habitat suitability (Elith et al. 2006; Pearson 2007). Yet, they still require a minimum, variable, number of data points. Therefore, we used known occurrence points, instead of SDMs, for species with less than 10 points, to avoid the creation of models with high uncertainty (Mateo et al. 2013). A total of 178 SDMs were performed, including 50 bryophytes, 49 vascular plants, 13 molluscs and 66 arthropods (Appendix S2).

To model species distributions, we used the MaxEnt algorithm and application version 3.3.3 (Phillips et al. 2004), developed to model species distributions with presence-only data, applying the principle of maximum entropy (Elith $\mathrm{et} \mathrm{al}$. 2006).

The selection of input variables was based on available data for the Azores and the results from the Project SMARTPARKS (Calado et al. 2014 b). Three climatic and three geographic variables were used as the most meaningful measures across all taxonomic groups. The climatic variables - annual averages from the past for maximum annual temperature (tmax), minimum annual precipitation (ppmin), and annual range of precipitation (pprange) - were obtained from the CIELO Model for the Azores (Azevedo 1996), which models local scale climate variables and has successfully modelled species distributions in the Azores (Fattorini et al. 2012). Since orography has a major influence on the climate of the Azorean islands, strong climatic differentiation can be observed in altitude as well as significant climatic asymmetries inland on each island (Azevedo 1996). To avoid collinearity and spatial autocorrelation of variables (Barry \& Elith 2006), temperature was used instead of elevation.

The geographic variables - land use, slope and distance to the sea - were developed based on land use and altimetry maps provided by the Azorean Government agencies. All explanatory variables were converted to a $500 \mathrm{~m} \times 500 \mathrm{~m}$ resolution, the same grid as species data, using DIVA-GIS (Hijmans et al. 2001).

Land use is one of the most important factors affecting the distribution of species in the Azores (Cardoso et al. 2013), and using data on this variable is a way to approximate potential and realized distributions of species. It was assumed that the main changes in land use in the Azores had occurred before the 1960s (Soeiro de Brito 2004), and limiting the data to the last five decades minimized the risk of using location points where the species most likely no longer reside due to habitat destruction. For this reason we adopted a two-step approach to perform SDMs (Fig. 2). The first step consisted of performing two SMDs for each species. The first was with climatic variables only (tmax, ppmin and pprange), using all known occurrence points that comply with accuracy requirements and all the climatic range, considering the absence of studies on the past climate variability for the Azores; and the other with geographical variables only (land use, slope and sea distance) using occurrence points since 1960 , to avoid the prediction of the occurrence of species where past land use change has possibly eliminated them. Both these probabilistic maps (climatic and geographic) were converted to presence/absence using the value that maximized the sum of sensitivity and specificity for each species as the threshold (Liu et al. 2013). The second step consisted of combining both maps, with each species considered present only in the cells deemed as suitable in both climatic and geographic maps.

Models were run using a maximum number of background points of 1000 considering the small size of the island. The remaining parameters of the MaxEnt application were maintained at default settings. In order to test the performance of the model, data points were split into training and testing datasets, with 80 and $20 \%$ of the points, respectively.

All final models of each taxonomic group were analysed by an expert researcher, based on their knowledge of the species. The experts considered were researchers working specifically on the Azores archipelago with profound knowledge of relevant species and several peer-reviewed scientific publications on them. The accuracy of the resulting models was also assessed using the area under the curve (AUC) of the receiver operating characteristic (ROC) (Elith et al. 2006). Based on Swets (1988), most models with AUC values lower than 0.7 were ignored, and only the occurrence points of corresponding species were used. However, for 
presence-only data, the maximum AUC is less than one and is smaller for wider-ranging species (Phillips et al. 2004). Based on that assumption and the expert researchers' validation, exceptions were made for species that were widespread in the Azores and represented by a high number of occurrences (e.g., bryophytes: Andoa berthelotiana, Fissidens asplenioides, Radula carringtonii; vascular plants: Erica azorica, Hedera azorica, Ilex perado subsp. azorica, Laurus azorica; molluscs: Lauria fasciolata, Leiostyla fuscidula; arthropods: Argyresthia atlanticella, Ascotis fortunata azorica, Cyclophora azorensis) (Appendix S2).

\section{Conservation targets for species}

In spatial conservation planning, a species conservation target is usually the amount of a species' range that must be included within a reserve system to be considered as sufficiently protected (Fajardo et al. 2014). A target value of $12 \%$ was previously set for non-endangered taxa by Vasconcelos $\mathrm{et} \mathrm{al}$. (2012), although the authors did recognize that this figure has no established scientific validity to assure that populations selected for conservation are viable. The use of variable targets regarding taxon ranges has been advocated previously (Rodrigues et al. 2004).

Based on a previous methodology, species conservation targets were defined to reflect the context of each species in the archipelago and their current conservation status, and to perform an individual species assessment of the PA network (Fajardo et al. 2014). The target for each species was a weighted average of three partial targets (Appendix S3): (1) Number of islands where the species occurs. Values varied between a maximum of $100 \%$ for species occurring only on the island being studied, and a minimum of $20 \%$ for species occurring on all nine islands of the archipelago; (2) Inclusion in official conservation strategies and plans. Legal documents, despite their legal importance, identify species in a more global context and less in accordance with the Azorean reality. Therefore, a maximum of $100 \%$ was assigned to species identified in Cardoso et al. (2008), who prioritized 100 species for conservation in the Azores. A total of $75 \%$ was assigned to species simultaneously identified in at least one international legal document and the regional legal document for nature conservation (Appendix II of the Regional Legislative Decree No. 15/2012/A). A total of 50\% was assigned to species identified in at least one international legal document or the regional legal document for nature conservation; (3) Conservation status. A partial target was also assigned to species identified as threatened in the Azorean Biodiversity Portal: $100 \%$ to E, $90 \%$ to R, $70 \%$ to T, $50 \%$ to RT, $30 \%$ to $\mathrm{V}$ and $10 \%$ to NT. We also considered a $30 \%$ value for those species not identified as threatened but included in the priority species for conservation in the Azores (Cardoso et al. 2008), where the distribution area is in decline.

The same expert researchers, who were requested to validate SDMs, scored the partial targets from $0-100 \%$. The final value for each species was then calculated weighting the corresponding partial targets. The 'number of islands with occurrence' was weighted with 0.35 . The 'inclusion in official conservation strategies and plans' was weighted with 0.35 . And the 'conservation status' was weighted with 0.30 . The final conservation target, corresponding to the minimum percentage of each species range on the island that should be included inside PAs, was then used to individually assess the coverage of current PA limits.

\section{Assessment of protected area networks}

\section{Individual species assessments}

A species-focused assessment of the current PAs on Pico Island was performed, evaluating how much of the predicted area of occurrence (for species with SDM) and the occurrence pixels (for species without SDMs) are currently protected and how the current INP limits contribute to the proposed conservation targets. For each species, the percentage of the predicted occurrence area inside PAs was calculated and compared with the conservation target. When the percentage of the predicted area inside PAs was lower than the proposed target, species were considered poorly protected.

In addition, a null model analysis (Gotelli et al. 1996) was also performed to test whether the number of protected cells per species was significantly different (lower or higher) from what was expected if PAs were randomly distributed in space. To do this, the predicted occurrence area inside PAs for each species was compared with the values obtained from 1000 random distributions of protected cells, with the number of cells in each run equalling the number of cells currently protected. A species was considered more protected than expected by chance if its coverage by current PAs was higher than the 0.975 percentile of randomizations and less protected than expected if it was lower than the 0.025 percentile among all random runs.

\section{Efficiency of protected areas}

In order to estimate the efficiency of Pico's PAs, we used the Prion software (PRIority Optimization aNalysis) (P. Cardoso, in preparation 2016), which uses a stochastic global optimization technique based on genetic algorithms to maximize the representation of features of interest (species), while minimizing the costs of each option (in the simplest case, the number of cells to be protected) and the perimeterto-area ratio as a surrogate for connectivity between protected patches. Representation of features is calculated by attributing a target value to each (number of cells, abundance, probability of presence, etc.). A weighted combination of representation, cost and connectivity results in a fitness value for each solution explored by the algorithm. In this particular implementation, the analysis is spatially explicit in the sense that all steps of the algorithm, namely crossover and mutation, are made directly using the spatial raster layers. Crossover was made by randomly choosing two columns and two rows in the raster layers of the parent solutions and masking all cells in between both. The offspring solution inherited the PA placement 
inside the mask from one of the parents and the placement outside the mask from the other parent. Mutation was applied by randomly placing a similar mask over any offspring member with a given low probability. All cells inside the mask change value, in this case from selected to non-selected and vice versa.

The assessment of the efficiency of current PAs was performed in two different ways. The first was a typical minimum set cover problem. We compared the extent (here used as cost measure) of current PAs with the extent of a quasi-optimal solution that minimized the protected number of cells while protecting the same average proportion of each species' range. This average proportion was used as a target in the analysis, with solutions being restricted to those that left it fulfilled (hereinafter designated as 'minimum set'). The ratio between the extent (number of cells protected) of the quasi-optimal solution and the extent of current PAs reflects the efficiency of PAs, with the ratio being 1 if current PAs were as good as the best solution found by Prion, and 0 if PAs were simply unnecessary to reach targets (a purely theoretical scenario).

The second approach was a typical maximal coverage problem. We compared the average of the proportions of species' protected ranges with an optimal solution that maximized species coverage with similar costs. The number of protected cells (costs) in the current PAs was used as a restriction in Prion (hereinafter designated as 'maximal coverage'). The ratio between the current and the quasioptimal percentages of targets reached reflected the efficiency of current PAs, with the ratio being 1 if current PAs were as good as the best solution found by Prion, and 0 if PAs did not reach any target or fraction of it.

Both the 'minimum set' and 'maximal coverage' were run for each individual taxonomic group and for the complete set of species in the study. The statistical significance of results was also assessed comparing them to the outcomes from null models (see 'Individual species assessments' section) in order to assess if these solutions were better than expected by chance in achieving overall and species targets.

\section{Hierarchical prioritization of areas for conservation}

The software for spatial conservation prioritization Zonation version 4 (Moilanen et al. 2009) was used to prioritize Pico's areas, running the model both for all taxonomic groups together and for each taxonomic group separately. The Zonation algorithm produces a hierarchical prioritization of the landscape, ranking cells on a scale from 0 to 1 , where the highest ranked have the highest conservation value (Moilanen et al. 2009).

To perform the analysis, the additive-benefit function was selected as a removal rule. The option edge removal was selected to generate spatial aggregation into the solution. The warp factor and the boundary length penalty strength were defined as 1 and 0.01 , respectively (Moilanen et al. 2014). All species were weighted equally, and the target was the entire predicted occurrence area.

\section{RESULTS}

\section{Species distribution models and conservation targets}

AUC values for test data varied between 0.222 (arthropod Drouetius borgesi centralis) and 1.000 (vascular plant Silene uniflora subsp. cratericola - a subspecies that, so far, is only found at the top of Mount Pico) (Appendix S2). Most of the species presenting AUC values lower than 0.7 were widespread on Pico Island and had a large number of occurrence points. Therefore, and after expert opinion analysis of the models' results, only four SDMs (all arthropods: Crotchiella brachyptera, Drouetius borgesi centralis, Megaselia leptofemur, Pseudosinella azorica) were not used in further analyses considering that SDMs presented both AUC values inferior to 0.7 and a small number of samples. For these four species, we used occurrence points in subsequent analyses.

The proposed conservation targets varied between $7 \%$ (for 27 species, mainly vascular plants and arthropods) and $86 \%$ (for two bryophytes and one vascular plant) of the species' predicted occurrence area (Appendix S3).

\section{Assessment of protected areas network}

\section{Individual species assessments}

Only 53 species (eight bryophytes, eight vascular plants, one mollusc, 33 arthropods and three vertebrates) had $75 \%$ or more of their predicted distribution area inside the INP limits (Fig. 3 and Appendix S4). Molluscs were the taxonomic group with the fewest species represented, and only three taxa had more than $50 \%$ of their occurrence areas inside INP limits. Arthropods are the most numerous group and were the taxonomic group with the highest number of species (33 taxa) with more than $75 \%$ of their occurrence area inside INP current limits. Predicted occurrence areas of six taxa (two vascular plants: Platanthera azorica and Taxus baccata; and four arthropods: Atlantocis gillerforsi, Homoeosoma picoensis, $P$. vulcanus and $T$. pereirai) were completely outside INP limits.

A large number of conservation targets $(83 \%)$ were achieved, relating to181 species with at least a percentage of their predicted occurrence areas defined by their conservation targets inside the current limits of Pico's PAs (Table 1).

Null models showed that, while $56 \%$ of species were better represented in the current INP than what could be expected from a random placement of protected cells, the percentage improved to 66 and $68 \%$ for the 'minimum set' and 'maximal coverage' solutions, respectively (Table 2). Plants (bryophytes: 82,88 and $88 \%$; and vascular plants: 61,70 and $72 \%$ ) were the taxonomic groups with a larger percentage of species better represented in all solutions, followed by arthropods, vertebrates and molluscs with the lowest percentages.

\section{Efficiency of protected areas}

Based on Prion software, the efficiency of Pico's PAs varied between 66 and $78 \%$, for 'minimum set' and 'maximal 
Figure 3 Number of species and the percentage intervals of occurrence area for taxonomic groups inside the current INP limits.

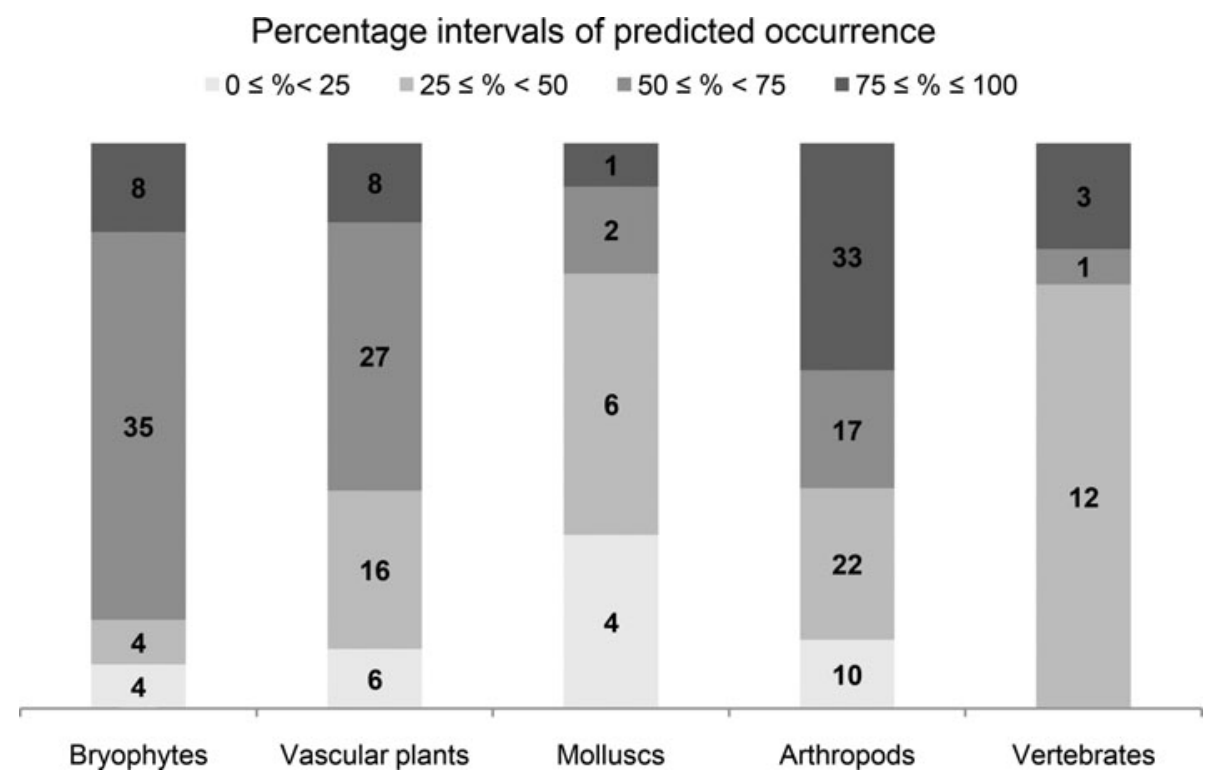

Table 1 Species-focused assessment, considering conservation targets defined in this study, for each taxonomic group and for the complete set of species in the current PA network of Pico Island.

\begin{tabular}{|c|c|c|c|c|}
\hline \multirow[t]{2}{*}{ Taxonomic group } & \multicolumn{2}{|c|}{ Species achieving conservation targets } & \multicolumn{2}{|c|}{ Species not achieving conservation targets } \\
\hline & Number of species & Percentage (\%) & Number of species & Percentage (\%) \\
\hline Bryophytes & 42 & 82 & 9 & 18 \\
\hline Vascular plants & 47 & 82 & 10 & 18 \\
\hline Molluscs & 10 & 77 & 3 & 23 \\
\hline Arthropods & 72 & 88 & 10 & 12 \\
\hline Vertebrates & 10 & 63 & 6 & 38 \\
\hline Complete set of species & 181 & 83 & 38 & 17 \\
\hline
\end{tabular}

Table 2 Null model analysis for each taxonomic group and for the complete set of species in the current PA network of Pico Island ('current INP'); in the quasi-optimal solution that minimized the protected number of cells while protecting the same average proportion of each species' range ('minimum set'); and in the optimal solution that maximized species coverage with similar costs ('maximal coverage'). ' + ' $=$ number and percentage of species with observed value better than what could be expected by random placement of protected cells; '-' = number and percentage of species with observed value worse than what could be expected by random placement of protected cells; ' $=$ ' = number and percentage of species with observed value not different from what could be expected by random placement of protected cells.

\begin{tabular}{|c|c|c|c|c|c|c|c|c|c|c|}
\hline \multirow[t]{2}{*}{ Taxonomic group } & \multicolumn{3}{|c|}{ Current INP } & \multicolumn{3}{|c|}{ 'Minimum set' } & \multicolumn{3}{|c|}{ 'Maximal coverage' } & \multirow[t]{2}{*}{ Total } \\
\hline & + & - & $=$ & + & - & $=$ & + & - & $=$ & \\
\hline Bryophytes & $42(82 \%)$ & $5(10 \%)$ & $4(8 \%)$ & $45(88 \%)$ & $4(8 \%)$ & $2(4 \%)$ & $45(88 \%)$ & $3(6 \%)$ & $3(6 \%)$ & $51(100 \%)$ \\
\hline Vascular plants & $35(61 \%)$ & $12(21 \%)$ & $10(18 \%)$ & $40(70 \%)$ & $14(25 \%)$ & $3(5 \%)$ & $41(72 \%)$ & $10(18 \%)$ & $6(11 \%)$ & $57(100 \%)$ \\
\hline Molluscs & $3(23 \%)$ & $10(77 \%)$ & $0(0 \%)$ & $4(31 \%)$ & $7(54 \%)$ & $2(15 \%)$ & $4(31 \%)$ & $5(38 \%)$ & $4(31 \%)$ & $13(100 \%)$ \\
\hline Arthropods & $40(49 \%)$ & $9(11 \%)$ & $33(40 \%)$ & $49(60 \%)$ & $11(13 \%)$ & $22(27 \%)$ & $52(63 \%)$ & $7(9 \%)$ & $23(28 \%)$ & $82(100 \%)$ \\
\hline Vertebrates & $3(19 \%)$ & $5(31 \%)$ & $8(50 \%)$ & $7(44 \%)$ & $5(31 \%)$ & $4(25 \%)$ & $7(44 \%)$ & $4(25 \%)$ & $5(31 \%)$ & $16(100 \%)$ \\
\hline $\begin{array}{l}\text { Complete set of } \\
\text { species }\end{array}$ & $123(56 \%)$ & $41(19 \%)$ & $55(25 \%)$ & $145(66 \%)$ & $41(19 \%)$ & $33(15 \%)$ & $149(68 \%)$ & $29(13 \%)$ & $41(19 \%)$ & $219(100 \%)$ \\
\hline
\end{tabular}

coverage' solutions, respectively (Table 3 and Appendix S5). Current PAs covered a higher extent to achieve the same targets as the quasi-optimal solutions, but for the same percentage of protected territory, they assured the achievement of fewer targets than quasi-optimal solutions. For all situations, in the complete set of species and individual taxonomic groups, having targets as a restriction resulted in lower values of efficiency in the 'minimum set' than in the 'maximal coverage' solution.

In both approaches, similarly to the null model analyses, bryophytes and vascular plants were the two groups best represented by current PAs, followed by arthropods and 
Table 3 Efficiency of Pico's INP for each taxonomic group and the complete set of species in the quasi-optimal solution that minimized the protected number of cells while protecting the same average proportion of each species' range ('minimum set'); and in the optimal solution that maximized species coverage with similar costs ('maximal coverage'). P ncells = Number of protected cells; QoS = Quasi-optimal solution.

\begin{tabular}{|c|c|c|c|c|c|c|}
\hline \multirow[t]{3}{*}{ Taxonomic group } & \multicolumn{6}{|c|}{ Efficiency of Pico's $P A s$} \\
\hline & \multicolumn{3}{|c|}{ 'Minimum set' } & \multicolumn{3}{|c|}{ 'Maximal coverage' } \\
\hline & Pncells (INP) & $\begin{array}{l}\text { P ncells to reach } \\
\text { same \% targets } \\
(Q o S)\end{array}$ & $\begin{array}{l}\text { Efficiency } \\
(\%)\end{array}$ & $\begin{array}{l}\text { Average targets (\%) } \\
\text { achieved (INP) }\end{array}$ & $\begin{array}{l}\text { Average targets (\%) } \\
\text { achieved with same } \\
\text { number of cells (QoS) }\end{array}$ & $\begin{array}{l}\text { Efficiency } \\
(\%)\end{array}$ \\
\hline Bryophytes & 746.0 & 429.0 & 57.5 & 62.1 & 83.5 & 74.4 \\
\hline Vascular plants & 831.0 & 505.0 & 60.8 & 55.7 & 73.7 & 75.6 \\
\hline Molluscs & 580.0 & 216.0 & 37.2 & 36.7 & 64.1 & 57.3 \\
\hline Arthropods & 824.0 & 361.0 & 43.8 & 60.4 & 82.0 & 73.7 \\
\hline Vertebrates & 835.0 & 235.0 & 28.1 & 49.3 & 87.2 & 56.5 \\
\hline $\begin{array}{l}\text { Complete set of } \\
\text { species }\end{array}$ & 853.0 & 563.0 & 66.0 & 57.4 & 73.4 & 78.2 \\
\hline
\end{tabular}

molluscs, with vertebrates having the lowest efficiency values.

\section{Hierarchical prioritization of areas for conservation}

The INP's current area covers about $55 \%$ of the cells, with the highest rank (in the last quartile: 0.75-1) (Appendix S6) mainly in the central zone of the island (Fig. $4(a)$ ). Several high-ranked areas (about 45\% of cells in the last quartile) were identified outside the INP, mainly in the western zone of Mount Pico (Fig. $4(a)$ ).

Bryophytes were the taxonomic group with the greatest number of highly ranked areas (about $66 \%$ in the last quartile) covered by current INP limits, mainly located in the central zone of the island (Fig. $4(b)$ ). Vascular plants (Fig. $4(c)$ ), arthropods (Fig. $4(e)$ ) and vertebrates (Fig. $4(f)$ ) had about 54,53 and $42 \%$, respectively, of highly ranked areas (in the last quartile) covered by current INP limits. Molluscs were the taxonomic group with the lowest percentage of highly ranked areas (about $30 \%$ in the last quartile) covered by INP limits (Fig. $4(d))$.

\section{DISCUSSION}

Overall, Pico's current INP does not ensure the conservation of all taxa, six of which live completely outside its limits, and there are important areas for conservation outside current PA limits. Similar results were found in other studies focusing on particular taxonomic groups in the Azores (Borges et al. 2000; Gaspar et al. 2011; Fattorini et al. 2012; Crespo et al. 2014).

One of the benefits of the methodological framework presented here is the integrated use of a large number of species of different taxonomic groups, many of them not legally prioritized or emblematic, giving a broader view of the PAs' efficiency. Proposals to change PA limits based on a large number of species may lead to the protection of wider areas in order to ensure that all species fulfil individual conservation targets. Such proposals may become impractical when integrating socio-economic considerations, mostly related to territory constraints of small islands. However, including only emblematic species or a single taxonomic group may also underestimate the conservation needs of other species that may be essential for the functioning of the whole ecosystem.

Regarding conservation targets for species, the methodological framework considers each species in the context of the island and the archipelago. It seems to be applicable to small islands, and adaptable to other territories, with room for continued improvement in future studies, which is in line with Rodrigues et al. (2004), who advocated the use of variable targets regarding taxon ranges instead of fixed targets lacking scientific validity (Vasconcelos et al. 2012). The lack of information and legal support creates a bias from the beginning of the process when there is little available information, which may be overcome with new, focused studies. For example, in order to tackle possible sampling biases, spatial autocorrelation of points could have been performed. The use of a robust method, such as species occurrence thinning (Aiello-Lammens et al. 2015), to overcome possible spatial sampling biases in the Atlantis Database is recommended under the Atlantis Database Project. Finally, using information on the prevalence of species (Phillips et al. 2013; Elith et al. 2006) and calculating measures such as the true skill statistic (Alouche et al. 2006) could allow better quantification regarding the accuracy of models.

The generally lower values defined as conservation targets for molluscs and arthropods result from the low values of the partial targets 2 and 3 (inclusion in official conservation strategies and plans and conservation status, respectively), due to the lack of a national or regional catalogue of endangered species and legislation covering these taxonomic groups, except those prioritized (Cardoso et al. 2008). Despite rarity and vulnerability (Cardoso et al. 2008), molluscs are hardly covered by international directives or conventions. The relatively lower values for molluscs and arthropods more accurately reflect the limitations of the current legislation 

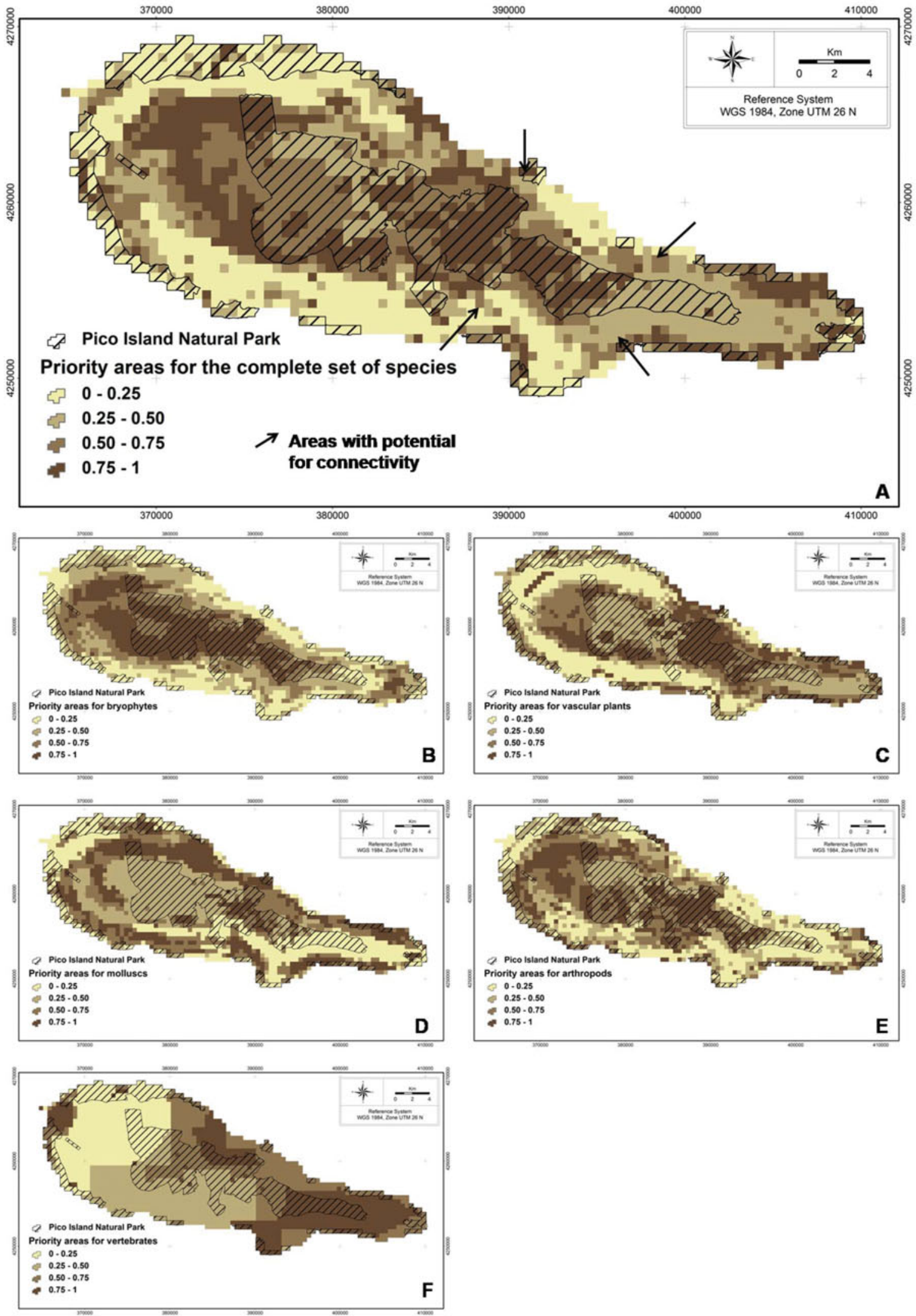

Figure 4 (Colour online) Ranking of areas for conservation obtained with zonation software: $(a)$ all species; $(b)$ bryophytes; $(c)$ vascular plants; $(d)$ molluscs; $(e)$ arthropods; and $(f)$ vertebrates. 
and species threat analyses than their inherent conservation interest. Arthropods have a high ratio of achieved targets almost certainly due to the low targets defined, and not their high occurrence inside PAs (Figs $4(d)$ and $(e)$ ).

There was consistency throughout the analysis, whether considering individual species assessments or the efficiency of PAs. Null models from Prion software for individual species, for both 'targets' and 'costs' solutions had more species that were better represented than in INP solutions, suggesting that there is still room to improve current PAs for assessed species. Additionally, considering efficiency values for the current INP, there is room for improvement, especially for vertebrates and molluscs. The redefinition of current INP limits may be timely, considering that the quasi-optimal solutions achieve both higher coverage with similar extent and similar coverage with smaller extent of PAs. Naturally, from the point of view of nature conservation, the ideal solution is to extend current limits, increasing target achievements, particularly for underrepresented taxa.

The central zone of the island is where priority areas identified by Zonation software are located, overlapping most PAs classified as nature reserves (see Fig. S1.1 in Appendix S1 for the location of classified PAs). In general, PAs classified for species and habitat management also overlap identified priority areas. Protected landscapes for vineyard culture have higher and lower rankings, depending on their location. Although protected landscapes were classified due to the human interaction with the landscape (Regional Legislative Decree No. 15/2012/A), results suggested that protected landscapes for vineyard culture with higher ranking values (PICO14 and PICO15 - see Fig. S1.1 in Appendix S1 for area codes) have potential for active conservation measures towards recovery ecosystem. On the other hand, protected landscapes for vineyard culture with lower ranking values (PICO16 and PICO18) are the largest on the island and are located around Madalena, the main village of Pico Island. Considering the low ranking of these two PAs, and excluding other social and environmental factors, both of these protected landscapes seem to have less potential for conservation and, thus, less potential for conflicts with existing human activities.

Among the high-ranked areas identified outside the INP, the most important, located in the western part of the island, corresponds mainly to pastures and some areas occupied by invasive or other exotic species, which were not used in the current analysis. They do however have the potential to harbour species here considered as priority, increasing the value of those areas for conservation and eventual restoration of natural forest. High-ranked areas identified suggest that active measures, mainly in those areas occupied by alien invasive species, would be advantageous to promote the conservation of native species. This may not only decrease the invasion in invaded areas, but also establish a buffer zone around PAs in order to decrease the exposure to invasion. Urban development and agricultural lands surrounding PAs increase their 'island' effect, rendering them more vulnerable to the loss of species (Mulongoy et al. 2004). The aggressive behaviour of invasive species may intensify the pressure. In general, the analysed species would benefit from an extension of the INP limits to the western side of Mount Pico. Several vascular plants with high conservation values (e.g., Azorina vidalii, Corema album azoricum and Myosotis maritima) occupy only coastal areas, where most urban areas and several economic activities are located. In fact, the coastal zone is the most used and impacted area on the island (and all the Azorean islands, in general), resulting in a high degree of conflict between conservation and development objectives, which needs careful consideration.

Additionally, some of those high-ranked areas (identified with arrows in Fig. $4(a)$ ) seem to have potential for the establishment of corridors between central and coastal PAs and, in some way, (re)establish a natural link between both the north and the south coasts. Some coastal PAs (e.g., PICO09, PICO12 and PICO13) were created with the aim of managing species and habitats, and are relatively small. If it is impractical to increase the size of these areas (e.g., due to social and economic constraints), the existence of natural corridors promoting connectivity, even without having a legal protection status, will possibly bring positive impacts to the potential conservation areas (Damschen et al. 2006). These issues are important because, in anthropized landscapes, future species loss may occur even if the current landscape is maintained with inadequate connectivity (Lindborg et al. 2004). Molluscs, arthropods and vertebrates would all benefit from the corridors here identified and/or adjustments to current INP limits. Arthropods would also benefit from the extension of the INP limits to the western side of Mount Pico. The relatively large area outside INP limits (Figs $4(d)$ and $(e)$ ) suggest that the conservation objectives defined for molluscs and arthropods are demanding and, even if several species achieve their conservation objectives, there are other important biodiverse areas located outside INP boundaries (e.g., lava tubes). Connectivity areas could particularly benefit molluscs and arthropods due to their relatively small capacity to disperse. Undoubtedly, studies that are more detailed and that focus specifically on landscape connectivity (structural and functional) are necessary to corroborate these results and identify the best options for connectivity.

Land planning requires social-economic considerations (Wilson et al. 2010) which were not considered in this study. The hierarchical prioritization of areas for conservation identified areas with a high value for species conservation, which may trigger discussions concerning Pico's INP design, without limiting the results to a unique solution, and may allow for the consideration of other fundamental aspects of land planning. Some adjustments, changes and improvements in current resources management (e.g., halting the destruction of low altitude vegetation) and land use that might be limiting the achievements of conservation objectives could also be assessed in further analysis, even if hindered by the lack of human and economic resources, especially on small islands. 
The proposed methodological framework is not intended to solve the problem of endangered species in the short term. Active and immediate measures may be needed to reverse losses, but the main advantage of this strategy is the identification of several possible solutions with effects in the medium or long term, understandable by decision-makers and other stakeholders in an easy way. Monitoring studies and continuous assessment represent a key measure of the efficiency of PAs and, in this case, would support and confirm the need to clearly establish conservation targets.

The design of the new limits can be achieved via enlargement of the existing PAs, redrawing the limits of existing areas with no enlargement, or a mix of both methods. The first may be too simplistic and unrealistic due to strong limitations imposed by current island economic structure and land use. In fact, the spaces where the network should be enlarged are semi-natural pastures that are vital to the local economy, predominantly extensive cattle breeding. A second suggestion is redrawing without a significant enlargement of the total area. The current PA categories are established according to management objectives, and several features (with physical or geological interest) have been classified in the INP. Therefore, the design of new limits cannot consider only priority areas, but also the areas that might not have any endemic species conservation targets, but are of relevance regarding, for example, geological and cultural heritage. These constraints may be included in further studies.

Decision-makers and Pico Island local communities can now discuss how to implement conservation targets differently, ranging from new area limits of the INP to mainstreaming conservation targets into other spatial plans, namely the design of an ecological structure (COM 2013) on Municipal Master Plans.

\section{ACKNOWLEDGEMENTS}

The authors thank António Medeiros, Artur Gil and Regina Cunha for their contributions.

\section{Supplementary material}

To view supplementary material for this article, please visit http://dx.doi.org/10.1017/S037689291600014X

\section{References}

Aiello-Lammens, M.E., Boria, R.A., Radosavljevic, A., Vilela, B. \& Anderson, R.P. (2015) Functions for Spatial Thinning of Species Occurrence Records for Use in Ecological Models - Package, Version 0.1.0. [www document]. URL https://cran.r-project.org/ web/packages/spThin/spThin.pdf

Allouche, O., Tsoar, A. \& Kadmon, R (2006) Assessing the accuracy of species distribution models: prevalence, kappa and the true skill statistic (TSS). Fournal of Applied Ecology 43: 1223-1232.
Azevedo, E.B. (1996) Modelação do clima insular à escala local. Modelo CIELO aplicado à ilha Terceira. p. 247. PhD Thesis, University of Azores, Ponta Delgada, Portugal.

Barry, S. \& Elith, J. (2006) Error and uncertainty in habitat models. Fournal of Applied Ecology 43: 413-423.

Borges, P.A.V., Cunha, R., Gabriel, R., Martins, A.F., Silva, L. \& Vieira, V. (2005) A list of the terrestrial fauna (Mollusca and Arthropoda) and flora (Bryophyta, Pteridophyta and Spermatophyta) from the Azores. p. 317. Horta, Angra do Heroísmo and Ponta Delgada, Portugal: Direcção Regional do Ambiente and Universidade dos Açores.

Borges, P.A.V., Gabriel, R., Arroz, A.M., Costa, A., Cunha, R.T., Silva, L., Mendonça, E., Martins, A.M.F., Reis, F. \& Cardoso, P. (2010) The Azorean Biodiversity Portal: an internet database for regional biodiversity outreach. Systematics and Biodiversity 8 : 423-434.

Borges, P.A.V., Serrano, A.R.M. \& Quartau, J.A. (2000) Ranking the Azorean Natural Forest Reserves for conservation using their endemic arthropods. Fournal of Insect Conservation 4: 129-147.

Calado, H., Fonseca, C., Vergílio, M., Costa, A.C., Moniz, F., Gil, A. \& Dias, J.A. (2014 a) Small islands conservation and protected areas. Fournal of Integrated Coastal Zone Management/Revista de Gestão Costeira Integrada. 14: 167-174.

Calado, H., Vergílio, M., Fonseca, C., Gil, A., Moniz, F., Silva, S.F., Moreira, M., Bragagnolo, C., Silva, C. \& Pereira, M. (2014 b) Developing a planning and management system for protected areas on small islands (The Azores Archipelago, Portugal): the SMARTPARKS Project. Fournal of Integrated Coastal Zone Management/Revista de Gestão Costeira Integrada. 14: 335-344.

Calado, H., Lopes, C., Porteiro, J., Paramio, L. \& Monteiro, P. (2009) Legal and technical framework of Azorean protected areas. Proceedings of the 10th International Coastal Symposium, Lisbon, Portugal. Fournal of Coastal Research SI 56: 1179-1183.

Cardoso, P., Borges, P.A.V., Costa, A.C., Cunha, R.T., Gabriel, R., Martins, A.M.F., Silva, L., Homem, N., Martins, M., Rodrigues, P., Martins, B. \& Mendonça, E. (2008) A perspectiva arquipelágica-Açores. In: TOP 100 - as cem espécies ameaçadas prioritárias em termos de gestão na região europeia biogeográfica da Macaronésia, eds. J.L. Martín, M. Arechavaleta, P.A.V. Borges \& B. Faria, pp. 42-449. Consejería de Medio Ambiente y Ordenación Territorial, Gobierno de Canarias. [www document]. URL http://www.azoresbioportal.angra.uac.pt/files/noticias_Top\% 20100\%20Cap\%203\%20portugus.pdf

Cardoso, P., Rigal, F., Fattorini, S., Terzopoulou, S. \& Borges, P.A.V (2013) integrating landscape disturbance and indicator species in conservation studies. PLoS ONE 8: e63294.

COM (2013) Communication from the Commission to the European Parliament, the Council, the European Economic and Social Committee and the Committee to the Regions. Green infrastructure (GI) - enhancing Europe's natural capital. No 249 Final, Brussels, Belgium. [www document]. URL http://eur-lex.europa.eu/ legal-content/EN/TXT/?uri=COM:2013:0249:FIN

Condé, S. \& Richard, D. (2002) Biogeographical regions in Europe. The Macaronesian region - volcanic islands in the ocean. In: Report No 1/2002 - Europe's Biodiversity - Biogeographical Regions and Seas. EEA (European Environment Agency). [www document]. URL www.eea.europa.eu/publications/report_ 2002_0524_154909/biogeographical-regions-in-europe/ MacaronesiaReg.pdf

Costa, H., Medeiros, V., Azevedo, E.B. \& Silva, L. (2013) Evaluating ecological-niche factor analysis as a modeling tool for 
environmental weed management in island systems. Weed Research 53: 221-230

Council Directive2009/147/EC of 30 November 2009 on the conservation of wild birds. [www document]. URL http:// eur-lex.europa.eu/legal-content/EN/TXT/?uri=CELEX: 32009L0147

Council Directive 92/43/EEC of 21 May 1992 on the conservation of natural habitats and of wild fauna and flora. [www document]. URL http://eur-lex.europa.eu/legal-content/ EN/TXT/?uri=CELEX:01992L0043-20070101

Crespo, L.C., Bosmans, R., Cardoso, P. \& Borges, P.A.V. (2014) On three endemic species of the linyphiid spider genus Canariphantes Wunderlich, 1992 (Araneae, Linyphiidae) from the Azores archipelago. Zootaxa 3841: 403-417.

Damschen, E.I., Haddad, N.M., Orrock, J.L., Tewksbury, J.J. \& Levey, D.J. (2006) Corridors increase plant species richness at large scales. Science 313: 1284-1286.

Dudley, N. \& Parish, J. (2006) Closing the gap. Creating ecologically representative protected area systems: a guide to conducting the gap assessments of protected area systems for the Convention on Biological Diversity. Technical Series. No. 24, vi+108 pages. Montreal, Canada: Secretariat of the Convention on Biological Diversity. [www document]. URL www.cbd.int/doc/ publications/cbd-ts-24.pdf

Elith, J., Graham, C.H., Anderson, R.P., Dudík, M., Ferrier, S., Guisan, A., Hijmans, R.J., Huettmann, F., Leathwick, J.R., Lehmann, A., Li, J., Lohmann, L.G., Loiselle, B., Manion, G., Moritz, C., Nakamura, M., Nakazawa, Y., Overton, J.M.M., Townsend Peterson, A., Phillips, S.J., Richardson, K., ScachettiPereira, R., Schapire, R.E., Soberón, J., Williams, S., Wisz, M.S. \& Zimmermann, N.E. (2006) Novel methods improve prediction of species' distributions from occurrence data. Ecography 29: 129151.

Fajardo, J., Lessmann, J., Bonaccorso, E., Devenish, C. \& Muñoz, J. (2014) Combined use of systematic conservation planning, species distribution modelling, and connectivity analysis reveals severe conservation gaps in a megadiverse country (Peru). PLoS ONE 9: e114367.

Fattorini, S., Cardoso, P., Rigal, F. \& Borges, P.A.V. (2012) Use of arthropod rarity for area prioritisation: insights from the Azorean Islands. PLoS ONE 7: e33995.

Florencio, M., Cardoso, P., Lobo, J.M., Azevedo, E.B. \& Borges, P.A.V. (2013) Arthropod assemblage homogenization in oceanic islands: the role of exotic and indigenous species under landscape disturbance. Diversity and Distributions 19: $1450-1460$.

Gabriel, R., Homem, N., Couto, A., Aranda, S.C. \& Borges, P.A.V. (2011) Azorean bryophytes: a preliminary review of rarity patterns. Açoreana 7: 149-206.

Gaspar, C., Gaston, K.J., Borges, P.A.V. \& Cardoso, P. (2011) Selection of priority areas for arthropod conservation in the Azores archipelago. Fournal of Insect Conservation 15: 671-684.

Gotelli, N.J. \& Graves, G.R. (1996) Null models in ecology. Washington, D.C., USA: Smithsonian Institution Press.

Hijmans, R.J., Guarino, L., Cruz, M. \& Rojas, E. (2001) Computer tools for spatial analysis of plant genetic resources data: 1 . DIVA-GIS. Plant Genetic Resources Nemsletter 127: 15-19. [www document]. URL www.diva-gis.org/docs/pgr127_15-19.pdf

Kueffer, C., Daehler, C.C., Torres-Santana, C.W., Lavergne, C., Meyer, J.-Y., Otto, R. \& Silva, L. (2010) A global comparison of plant invasions on oceanic islands. Perspectives in Plant Ecology, Evolution and Systematics 12: 145-161.

Lindborg, R. \& Eriksson, O. (2004) Historical landscape connectivity affects present plant species diversity. Ecology 85: 1840-1845.

Liu, C., White, M. \& Newell, G. (2013) Selecting thresholds for the prediction of species occurrence with presence-only data. Fournal of Biogeography 40: 778-789.

Margules, C.R. \& Pressey, R.L. (2000) Systematic conservation planning. Nature 405: 243-253.

Mateo, R.G., Vanderpoorten, A., Muñoz, J., Laenen, B. \& Désamoré, A. (2013) Modeling species distributions from heterogeneous data for the biogeographic regionalization of the European bryophyte flora. PLoS ONE 8: e55648.

Moilanen, A., Kujala, H. \& Leathwick, J.R. (2009) The zonation framework and software for conservation prioritization. In: Spatial Conservation Prioritization - Quantitative Methods and Computational Tools, eds., A. Moilanen, K.A. Wilson \& H.P. Possingham. Oxford, UK: Oxford University Press.

Moilanen, A., Pouzols, F.M., Meller, L., Veach, V., Arponen, A., Leppänen, J. \& Kujala, H. (2014) Zonation - spatial conservation planning methods and software. Version 4. User Manual. C-BIG Conservation Biology, Informatics Group, Department of Biosciences, University of Helsinki, Finland. [www document]. URL http://cbig.it.helsinki.fi/files/ zonation/zonation_manual_v4_0.pdf

Mulongoy, K.J. \& Chape, S. (2004) Protected areas and biodiversity - an overview of key issues. CBD Secretariat, Montreal, Canada and UNEP-WCMC, Cambridge, UK. [www document]. URL http://www.ourplanet.com/wcmc/pdfs/protectedareas.pdf

Pearson, R.G. (2007) Species' distribution modeling for conservation educators and practitioners. Synthesis. American Museum of Natural History. [www document]. URL http://ncep.amnh.org

Phillips, S.J. \& Elith, J. (2013) On estimating probability of presence from use-availability or presence-background data. Ecology 94: 1409-1419.

Phillips, S.J., Dudík, M. \& Schapire, R.E. (2004) A maximum entropy approach to species distribution modeling. Proceedings of the 21st International Conference on Machine Learning, pp. 655-662. Banff, Canada. [www document]. URL www.cs.princeton.edu/ schapire/papers/maxent_icml.pdf

Pressey, R.L. (1994) Ad hoc reservations: forward or backward steps in developing representative reserve systems? Conservation Biology 8: 662-668.

Regional Legislative Decree No. 15/2012/A of 2 April. Establishes the Legal Regime of Nature Conservation and Biodiversity Protection. [www document]. URL http://dre.pt/pdf1sdip/2012/04/06600/0162501713.pdf

Rodrigues, A.S.L., Akçakaya, H.R., Andelman, S.J., Bakarr, M.I., Boitani, L., Brooks, T.M., Chanson, J.S., Fishpool, L.D.C., Fonseca, G.A.B., Gaston, K.J., Hoffmann, M., Marquet, P.A., Pilgrim, J.D., Pressey, R.L., Schipper, J., Sechrest, W., Stuart, S.N., Underhill, L.G., Waller, R.W., Watts, M.E.J. \& Yan, X. (2004) Global gap analysis: priority regions for expanding the global protected-area network. Bioscience Reports 54: 1092-1100.

Silva, L. \& Smith, C.W. (2006) A quantitative approach to the study of non-indigenous plants: an example from the Azores archipelago. Biodiversity Conservation 15: 1661-1679.

Soeiro de Brito, R. (2004) São Miguel - a ilha verde, estudo geográfico (1950-2000), 2nd Edition. Ponta Delgada, Portugal. 
Swets, J.A. (1988) Measuring the accuracy of diagnostic systems. Science 240: 1285-1293.

Vasconcelos, R., Brito, J.C., Carvalho, S.B., Carranza, S. \& Harris, D.J. (2012) Identifying priority areas for island endemics using genetic versus specific diversity - the case of terrestrial reptiles of the Cape Verde Islands. Biological Conservation 153: 276-286.
Whittaker, R.J. \& Fernández-Palacios, J.M. (2007) Island biogeography. Ecology, evolution and conservation. New York, USA; Oxford University Press.

Wilson, E. \& Piper, J. (2010) Spatial planning and climate change. The natural and built environmental series. Abingdon, UK: Routledge. 